\title{
VALIDATED REVERSE PHASE HIGH PERFORMANCE LIQUID CHROMATOGRAPHIC METHOD FOR THE SIMULTANEOUS DETERMINATION OF ARTEMETHER AND LUMEFANTRINE IN FIXED COMBINED DOSAGE FORM
}

\author{
VENKATA RAO $\mathrm{P}^{1 *}$, RAMBABU $\mathrm{C}^{2}$ \\ ${ }^{1}$ Department of Biochemistry, Acharya Nagarjuna Univesity, Guntur, Andhra Pradesh, India. ${ }^{2}$ Department of Chemistry, Acharya Nagarjuna \\ Univesity, Guntur, Andhra Pradesh, India. Email: pvr.payyavula@gmail.com
}

Received: 28 October 2016, Revised and Accepted: 25 November 2016

\begin{abstract}
Objective: The present aim is to develop simple, precise, and accurate reverse phase high performance liquid chromatographic method (RP-HPLC) for the simultaneous assay of artemether and lumefantrine in fixed combined dosage form.

Methods: The chromatographic study was carried out on Hypersil $\mathrm{C}_{18}$ column $(250 \times 4.6 \mathrm{~mm}, 5 \mu)$ with mobile phase containing a mixture of $\mathrm{KH}_{2} \mathrm{PO}_{4}$ buffer (pH-3.5) and acetonitrile in the ratio of $45: 55 \% \mathrm{v} / \mathrm{v}$ at a flow rate of $1.0 \mathrm{ml} /$ minute with ultraviolet detection at $218 \mathrm{~nm}$ in ambient column temperature.

Results: Using the optimized chromatographic conditions artemether and lumefantrine eluted with retention times of 2.207 and 3.733 minutes, respectively. The method was validated according to $\mathrm{ICH}$ guidelines with good reproducibility and linear responses, $\mathrm{y}=60.813 . \mathrm{x}+629.53\left(\mathrm{r}^{2}=0.9982\right.$ ) for artemether and $y=88.3108 . x+2370.2\left(r^{2}=0.9912\right)$. The $\%$ relative standard deviations of intra-day precision was ranged $0.378 \%$ and $1.26 \%$ for artemether and $0.459 \%$ and $1.15 \%$ for lumefantrine, respectively. The percentage recoveries were ranged from $99.96 \%$ to $100.02 \%$ for artemether and $99.96-99.97 \%$ for lumefantrine, respectively.
\end{abstract}

Conclusions: The developed RP-HPLC method was validated as per ICH guidelines and was found to be best suitable for pharmacokinetic studies of these mentioned drugs.

Keywords: Artemether, Lumefantrine, ICH guidelines.

(C) 2017 The Authors. Published by Innovare Academic Sciences Pvt Ltd. This is an open access article under the CC BY license (http://creativecommons. org/licenses/by/4. 0/) DOI: http://dx.doi.org/10.22159/ajpcr.2017.v10i3.15930

\section{INTRODUCTION}

Artemether, (Fig. 1), (3R,5aS,-6R, 8aS,9R,10S,12R,12aR)-decahydro10-methoxy-3,6,9- trimethyl- 3,12-epoxy-12H-pyrano [4,3-j]-1,2benzodioxepine is an antimalarial agent used to treatacute uncomplicated malaria [1,2]. The mechanism of action involves interaction of the peroxide-containing drug with heme, thereby resulting in the formation of a range of potentially toxic oxygen and carbon-centered radicals.

Azithromycin (Fig. 2), 2-(dibutylamino)-1-[(9Z)-2,7-dichloro-9-[(4chlorophenyl) methylidene]-9H-fluoren-4-yl]ethan-1-ol $[3,4]$ is an antimalarial agent used to treat acute uncomplicated malaria [3]. The exact mechanism by which lumefantrine exerts its antimalarial effect is unknown. It was assumed that lumefantrine inhibits the formation of $\beta$-hematin by forming a complex, thereby inhibiting nucleic acid and protein synthesis.

Combination of these two drugs is available in the local pharmacy in the brand name of combither oral tablets (artemether $20 \mathrm{mg}$ and lumefantrine $120 \mathrm{mg}$ ) used in the treatment of acute uncomplicated malaria caused by plasmodium falciparum [1,5].

Very few high performance liquid chromatographic (HPLC) methods were reported for the determination of artemether and lumefantrine in combination forms [6-11]. Basing on this accord, it made essential to develop a new reverse phase HPLC method (RP-HPLC) for routine analysis of the above said drugs in combined formulations, and in this accord, attempts were made by the author to develop simple, precise, and accurate RP-HPLC method for the simultaneous assay of the titled drugs and extended it for their determination in formulations.

\section{METHODS}

\section{Instrumentation}

The present chromatographic analysis was carried on water's 2695 HPLC system provided with Hamilton Syringe, Hypersil $\mathrm{C}_{18}$ column $(250 \times 4.6 \mathrm{~mm}, 5 \mu)$, auto sampler and 2996 photodiode array detector. Data were acquired and processed with Empower 2 software. Shimazdu electronic weighing balance (Model BL $220 \mathrm{H}$ ) was used for weighing the standards and samples. Elico pH meter (Hyderabad, India) LI 120 model was used for $\mathrm{pH}$ measurements.

\section{Chemicals and reagents}

Pharmaceutically grade pure sample of artemether and lumefantrine were obtained from Euphoria Healthcare and Spirochem Life sciences, Private Limited Mumbai, as gifted samples and their commercial dosage forms in the brand name of combither oral tablets (artemether $20 \mathrm{mg}$ and lumefantrine $120 \mathrm{mg}$ ) were procured from the local pharmacy. Milli-Q water, acetonitrile (HPLC grade), orthophosphoric acid (GR grade), and potassium dihydrogen orthophosphate monohydrate (GR grade) were obtained from Qualigens Ltd., Mumbai. All dilutions were performed in standard Class-A, volumetric glassware.

\section{Mobile phase preparation}

Prepare a filtered and degassed mixture of phosphate buffer (pH-3.5) and acetonitrile in the ratio of $45: 55 \% \mathrm{v} / \mathrm{v}$, respectively.

\section{Preparation of phosphate buffer}

The buffer was prepared by dissolving $2.72 \mathrm{~g}$ of potassium dihydrogen phosphate in $1000 \mathrm{ml}$ of milli-Q water. The $\mathrm{pH}$ of the buffer solution was adjusted to $3.5 \pm 0.05$ with ortho phosphoric acid. 
Diluent preparation

Mobile phase is used as diluent in the present assay.

\section{Preparation of stock and working standard solutions}

Standard stock solutions of the present studied drugs were prepared by weighing accurately $10 \mathrm{mg}$ of artemether and $20 \mathrm{mg}$ of lumefantrine were transferred into a clean and dry $100 \mathrm{ml}$ volumetric flask. To this flask, about $70 \mathrm{ml}$ of diluent was added and sonicated for 5 minutes. Later, the volume of the flask was made up to the mark with the same diluent (concentrations $100 \mu \mathrm{g} / \mathrm{ml}$ for artemether and $200 \mu \mathrm{g} / \mathrm{ml}$,

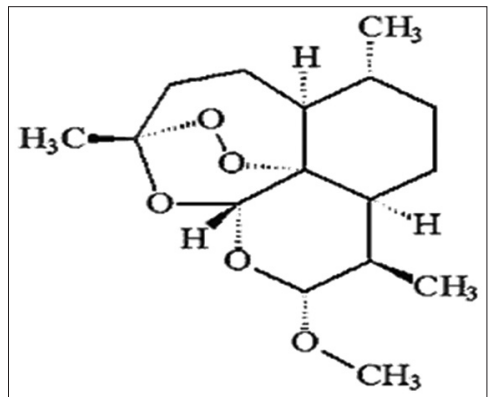

Fig. 1: Chemical structure of artemether

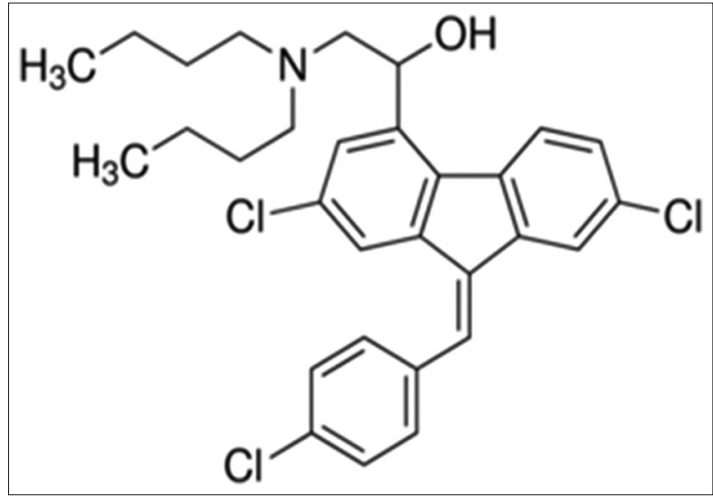

Fig. 2: Chemical structure of azithromycin for lumefantrine). From the above prepared stock solution pipette out and transfer suitable aliquots into a clean dry $10 \mathrm{ml}$ volumetric flask, and mixed with the same diluent to obtain final concentrations of $10-30 \mu \mathrm{g} / \mathrm{ml}$ for artemether and $20-60 \mu \mathrm{g} / \mathrm{ml}$, for lumefantrine, respectively.

\section{Preparation of sample solution}

20 tablets of combither oral tablets (artemether $20 \mathrm{mg}$ and lumefantrine $120 \mathrm{mg}$ ) purchased from the local pharmacy were powdered to fine powder. Then, sample solution was prepared by weighing and transferring equivalently $100 \mathrm{mg}$ of the fine powder of formulation mixture into a $100 \mathrm{ml}$ clean and dry volumetric flask containing $70 \mathrm{ml}$ of diluent and sonicated to dissolve it completely and the volume made up to the mark with the same solvent. From above prepared stock sample solution pipette out suitable aliquots and transferred into a clean and different dry $10 \mathrm{ml}$ volumetric flasks and diluted to the mark with the same diluent (concentration of $10-30 \mu \mathrm{g} / \mathrm{ml}$ for artemether and $20-60 \mu \mathrm{g} / \mathrm{ml}$ for lumefantrine), respectively. A volume of $20 \mu \mathrm{l}$ volumes of these sample solutions were injected five times and the peak areas were recorded.

\section{RESULTS AND DISCUSSION}

HPLC method development

In the development of the present method for the selected drugs a number of experimental trials were made by changing the columns and mobile phase by varying its composition as well as by changing the solvents. These trials had resulted in low resolution with asymmetric peaks and also peaks with more tailing factors and long elution times.

However, finally, the Hypersil $\mathrm{C}_{18}$ column $(250 \times 4.6 \mathrm{~mm}, 5 \mu)$ with mobile phase of $\mathrm{KH}_{2} \mathrm{PO}_{4}$ buffer ( $\left.\mathrm{pH}-3.5\right)$ and acetonitrile in the ratio of $45: 55 \% \mathrm{v} / \mathrm{v}$ at a flow rate of $1.0 \mathrm{ml} /$ minute and ultraviolet detection at a wavelength of $218 \mathrm{~nm}$ in ambient column temperature resulted in excellent elution of the two drugs with low retention and run times. The same buffer was used as diluent in the preparation of standard and sample solutions. With the above optimized conditions, the cited drugs (artemether and lumefantrine) were resolved with retention times (2.207 minutes and 3.733 minutes for artemether and lumefantrine, respectively) with theoretical plates and good resolution, respectively (Fig. 3).

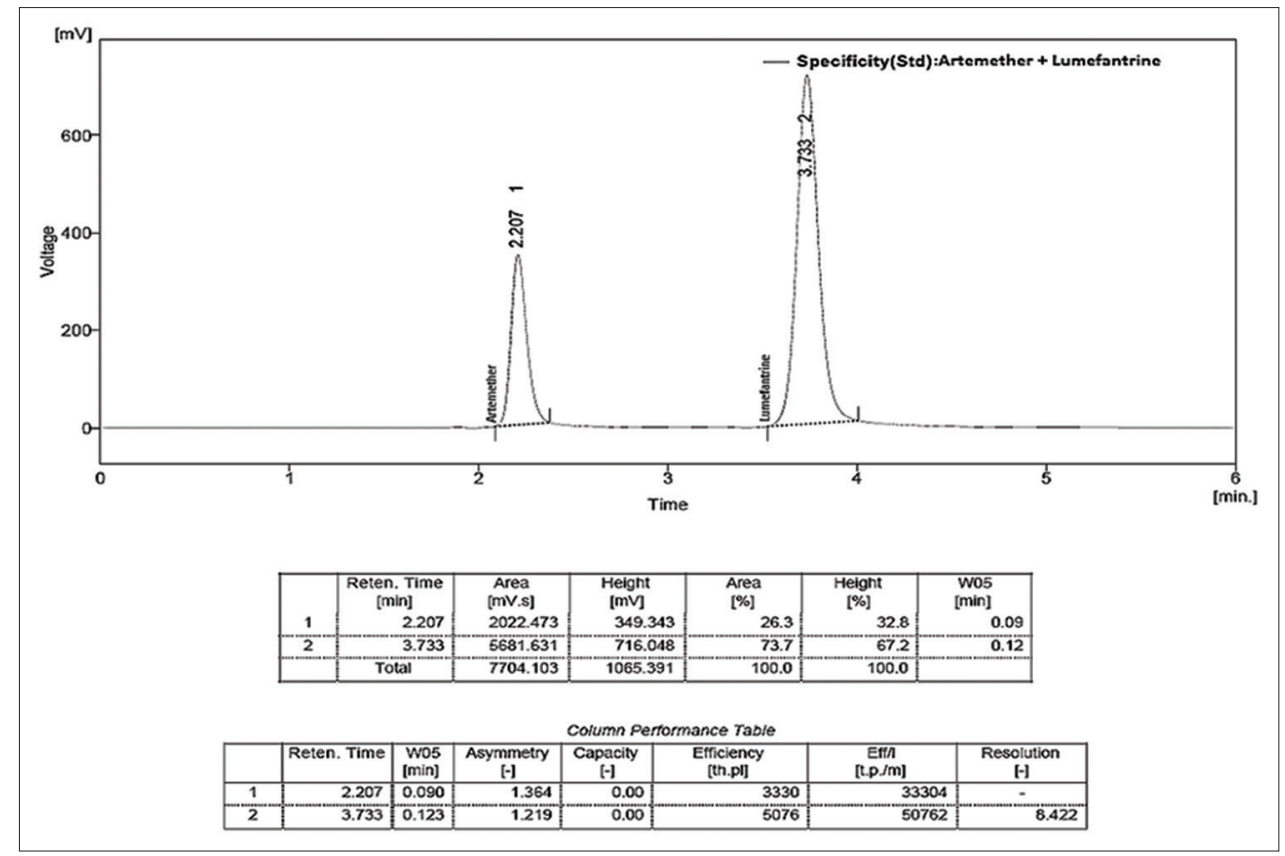

Fig. 3: Chromatogram of artemether and lumefantrine 
Method validation

The developed RP-HPLC method was validated in accordance with ICH guidelines [12] using the following parameters.

\section{System suitability}

System suitability parameters such as number of theoretical plates, HETP and peak tailing were determined for both the drugs with the proposed method and their values were tabulated in (Table 1), respectively. It was found that all the system suitability parameters for developed RP-HPLC method for artemether and lumefantrine were within the acceptance criteria.

\section{Specificity}

\section{Blank and placebo interference}

The specificity of the proposed method was established by injecting blank and placebo using the above chromatographic conditions. The chromatograms of blank and placebo solution showed no additional peaks at the retention time of artemether and lumefantrine peak revealing specificity of the developed RP-HPLC method.

\section{Linearity and detector response}

The linearity was performed by plotting, and calculating linear regression analysis for the standard curves of artemether and lumefantrine (Figs. 4 and 5), respectively. Two standard curves were obtained in the concentration range of $10-30 \mu \mathrm{g} / \mathrm{ml}$ for artemether and $20-60 \mu \mathrm{g} / \mathrm{ml}$ for lumefantrine, respectively. The slope and intercept value for calibration curve were $y=60.813 . x+629.53\left(r^{2}=0.9982\right)$ for artemether and $y=88.3108 . x+2370.2\left(r^{2}=0.9912\right)$ for lumefantrine, respectively. It was revealed that an excellent correlation exists between response factor and concentration of cited drugs within the concentration range indicated as above respectively (Table 2).

The limit of detection values for artemether and lumefantrine were found to be $0.0428 \mu \mathrm{g} / \mathrm{mL}$ and $0.0940 \mu \mathrm{g} / \mathrm{mL}$, respectively, and the limit of quantitation values for artemether and lumefantrine were found to be $0.1429 \mu \mathrm{g} / \mathrm{mL}$ and $0.3138 \mu \mathrm{g} / \mathrm{mL}$, respectively, revealing good sensitivity of the proposed method (Table 3).

Table 1: System suitability of artemether and lumefantrine

\begin{tabular}{lll}
\hline Parameters & Artemether & Lumefantrine \\
\hline Number of theoretical plates & 3330 & 5076 \\
Tailing factor & 1.36 & 1.219 \\
Area & 2022.473 & 5681.631 \\
Retention time & 2.207 & 3.733 \\
\hline
\end{tabular}

Table 2: Results of linearity of artemether and lumefantrine

\begin{tabular}{|c|c|c|c|}
\hline \multicolumn{2}{|l|}{ Artemether } & \multicolumn{2}{|l|}{ Lumefantrine } \\
\hline $\begin{array}{l}\text { Concentration } \\
\text { in } \mu \mathrm{g} / \mathrm{ml}\end{array}$ & $\begin{array}{l}\text { Peak area } \\
\text { ratio }\end{array}$ & $\begin{array}{l}\text { Concentration } \\
\text { in } \mu \mathrm{g} / \mathrm{ml}\end{array}$ & $\begin{array}{l}\text { Peak area } \\
\text { ratio }\end{array}$ \\
\hline 10 & 1244.648 & 20 & 4245.29 \\
\hline 15 & 1515.123 & 40 & 4900.04 \\
\hline 20 & 1875.465 & 60 & 5782.059 \\
\hline 25 & 2142.362 & 80 & 6951.37 \\
\hline 30 & 2451.356 & 100 & 7635.418 \\
\hline Slope, b & 60.813 & Slope, b & 88.310 \\
\hline Intercept, a & 629.53 & Intercept, a & 2370.2 \\
\hline Correlation, $\mathrm{r}^{2}$ & 0.9982 & Correlation, $\mathrm{r}^{2}$ & 0.9912 \\
\hline
\end{tabular}

Table 3: LOD and LOQ values of artemether and lumefantrine

\begin{tabular}{lll}
\hline Sensitivity Parameters & Artemether & Lumefantrine \\
\hline LOD $(\mu \mathrm{g} / \mathrm{ml})$ & 0.0428 & 0.142 \\
LOQ $(\mu \mathrm{g} / \mathrm{ml})$ & 0.094 & 0.313 \\
\hline
\end{tabular}

LOD: Limit of detection, LOQ: Limit of quantitation
Precision

The precision of the developed method was evaluated using intra-day analysis by injecting six replicate injections of $100 \%$ test concentration of the above mentioned drugs and the results were expressed in terms of standard deviation and \% relative standard deviation (\%RSD), respectively. From the results (\%RSD of 0.378 and $1.26 \%$ for artemether and 0.459 and $1.15 \%$ for lumefantrine), it was revealed that the developed method was found to be precise, respectively (Table 4).

\section{Accuracy}

The accuracy of the proposed method was determined at three concentration levels $(50,100$ and $150 \%)$ by recovery experiments which were carried out in triplicate preparations as per the proposed method. The percentage recoveries ranged from 99.96 to $100.02 \%$ for artemether and $99.96-99.97 \%$ for lumefantrine, respectively, revealing that the developed RP-HPLC method was found to be accurate (Table 5).

\section{Robustness studies}

The robustness studies for artemether and lumefantrine were established in the mentioned variance conditions $( \pm 2$ units change in flow rate and detection wavelength). From the results, it was observed that the assay values of the test preparation solution were not affected and it was in accordance with that of actual. System suitability parameters were also found satisfactory concluding robustness of the developed method (Table 6).

Solution stability study

The solution stability studies at $100 \%$ test concentration of the above mentioned drugs in mobile phase were carried out for $24 \mathrm{hrs}$ at $35^{\circ} \mathrm{C}$.

Table 4: Results of precision of artemether and lumefantrine

\begin{tabular}{|c|c|c|c|c|}
\hline \multirow{2}{*}{$\begin{array}{l}\text { Sample } \\
\text { number }\end{array}$} & \multicolumn{2}{|c|}{ Artemether } & \multicolumn{2}{|c|}{ Lumefantrine } \\
\hline & $\begin{array}{l}\text { Retention } \\
\text { time }\end{array}$ & Peak area & $\begin{array}{l}\text { Retention } \\
\text { time }\end{array}$ & Peak area \\
\hline Sample 1 & 2.213 & 2051.034 & 3.153 & 1828.32 \\
\hline Sample 2 & 2.190 & 2018.514 & 3.157 & 1879.004 \\
\hline Sample 3 & 2.210 & 2089.94 & 3.187 & 1874.11 \\
\hline Sample 4 & 2.203 & 2079.924 & 3.157 & 1833.076 \\
\hline Sample 5 & 2.21 & 2076.366 & 3.15 & 1848.682 \\
\hline Sample 6 & 2.203 & 2072.363 & 3.147 & 1865.499 \\
\hline \%Mean* & 2.205 & 2065 & 3.159 & 1855 \\
\hline $\mathrm{SD}^{*}$ & 0.008 & 26.0 & 0.015 & 21.4 \\
\hline$\% \mathrm{RSD}^{*}$ & 0.378 & 1.26 & 0.459 & 1.15 \\
\hline
\end{tabular}

*Average of six determinations. SD: Standard deviation

Table 5: Results of accuracy of artemether

\begin{tabular}{|c|c|c|c|c|}
\hline \multirow[t]{3}{*}{ Recovery level } & \multicolumn{4}{|c|}{ Artemether } \\
\hline & \multicolumn{2}{|c|}{ Amount added } & \multirow{2}{*}{$\begin{array}{l}\text { Amount } \\
\text { found }\end{array}$} & \multirow[t]{2}{*}{ \%Recovery } \\
\hline & Standard & Test & & \\
\hline $50 \%$ & 10 & 5.0 & 14.99 & 99.98 \\
\hline $100 \%$ & 20 & 5.0 & 25.03 & 100.02 \\
\hline $150 \%$ & 30 & 5.0 & 34.97 & 99.96 \\
\hline Mean recovery*\& \% RSD & $99.98 \%$ wi & $\% \mathrm{RSI}$ & $-0.0304 \%$ & \\
\hline \multirow[t]{3}{*}{ Recovery level } & \multicolumn{4}{|c|}{ Lumefantrine } \\
\hline & \multicolumn{2}{|c|}{ Amount added } & \multirow{2}{*}{$\begin{array}{l}\text { Amount } \\
\text { found }\end{array}$} & \multirow[t]{2}{*}{ \%Recovery } \\
\hline & Standard & Test & & \\
\hline $50 \%$ & 20 & 5.0 & 24.98 & 99.97 \\
\hline $100 \%$ & 40 & 5.0 & 44.97 & 99.97 \\
\hline $150 \%$ & 60 & 5.0 & 64.94 & 99.96 \\
\hline Mean recovery* \& \% RSD & \multicolumn{4}{|c|}{$99.96 \%$ with \%RSD-0.00504\% } \\
\hline
\end{tabular}

*Average of three determinations. RSD: Relative standard deviation,

SD: Standard deviation 


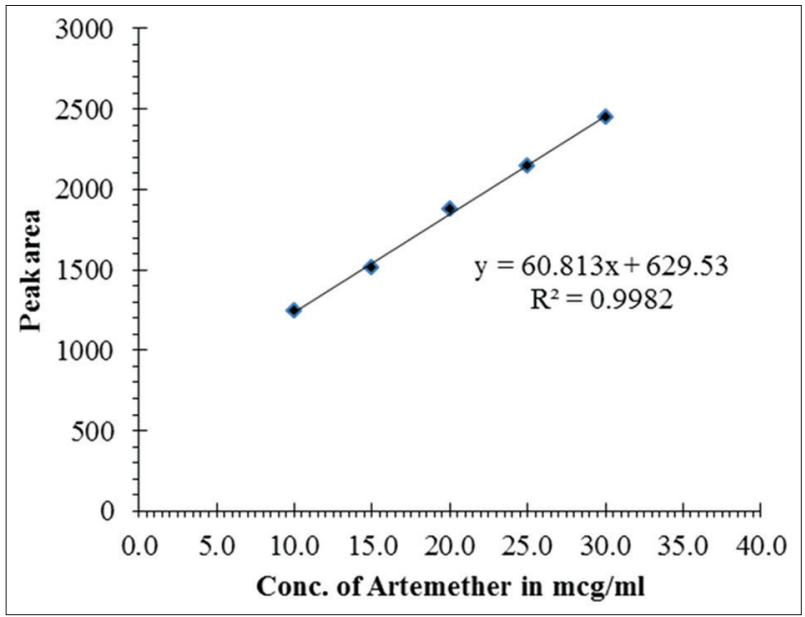

Fig. 4: Calibration curve of artemether

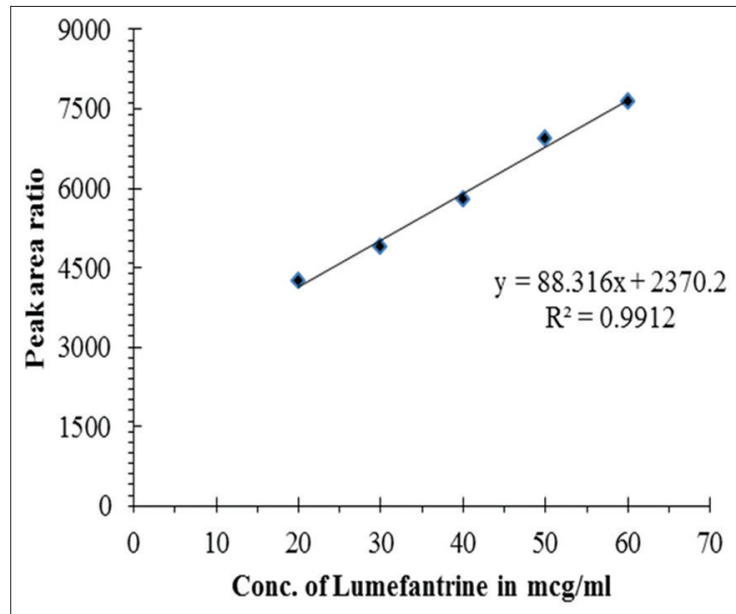

Fig. 5: Calibration curve of lumefantrine

Table 6: Results of robustness studies of artemether and lumefantrine

\begin{tabular}{|c|c|c|c|c|c|}
\hline \multirow[t]{2}{*}{ Chromatographic parameters } & \multirow[t]{2}{*}{ Changed value } & \multicolumn{2}{|c|}{ Retention time } & \multicolumn{2}{|l|}{ Tailing factor } \\
\hline & & Artemether & Lumefantrine & Artemether & Lumefantrine \\
\hline \multirow[t]{2}{*}{ Flow rate (ml/minute) } & 0.8 & 2.930 & 4.907 & 1.444 & 1.308 \\
\hline & 1.2 & 1.780 & 2.980 & 1.368 & 1.185 \\
\hline \multirow[t]{2}{*}{ Wavelength (nm) } & 216 & 2.223 & 3.710 & 1.36 & 1.219 \\
\hline & 220 & 2.203 & 3.207 & 1.409 & 1.219 \\
\hline
\end{tabular}

Table 7: Stability data of artemether and lumefantrine

\begin{tabular}{|c|c|c|c|}
\hline Drug & $\%$ Assay at $0 \mathrm{hr} *$ & $\%$ Assay at 24 hrs* & \% Deviation* \\
\hline Artemether & 99.40 & 99.94 & 0.99 \\
\hline Lumefantrine & 99.91 & 99.98 & 0.99 \\
\hline
\end{tabular}

*Average of six determinations

Table 8: Results for analysis in formulations

\begin{tabular}{lll}
\hline $\begin{array}{l}\text { Sample No. } \\
\text { Combither }\end{array}$ & Peak area & \\
\cline { 2 - 3 } & Artemether 20 $\mathbf{~ m g}$ & Lumefantrine 120 $\mathbf{~ g ~}$ \\
\hline 1 & 99.95 & 99.97 \\
2 & 99.84 & 100.05 \\
3 & 99.57 & 99.94 \\
Average* & 99.78 & 99.98 \\
SD* & 0.1955 & 0.0568 \\
\%RSD* & 0.195 & 0.0568 \\
\hline
\end{tabular}

*Average of three determinations. RSD: Relative standard deviation,

SD: Standard deviation

From the above studies, it was found that the mentioned analytes were stable in mobile phase for $24 \mathrm{hrs}$, indicating the solution stability (Mobile phase) of analysis in the proposed procedure (Table 7).

\section{Analysis of marketed formulation}

Analysis of marketed tablets Combither oral tablets (artemether $20 \mathrm{mg}$ and lumefantrine $120 \mathrm{mg}$ ) was carried out using the developed $\mathrm{sC}$ method. The \% drug content of artemether and lumefantrine in fixed combination dose tablets (combither) were found to be 99.78 and $99.98 \%$, respectively (Table 8)

\section{CONCLUSION}

A new simple, precise, and accurate RP-HPLC method was developed and validated for the assay of artemether and lumefantrine in fixed combination dose. The proposed method deduced high recoveries with good linearity and precision. The validation results cited above it were within ICH guidelines, concluding that the proposed RP-HPLC method was found to be suitable for the rapid analysis of artemether and lumefantrine in fixed combined formulations in quality control labs.

\section{ACKNOWLEDGMENTS}

The authors are thankful to Department of Chemistry, Acharya Nagarjuna University, Guntur for providing the technical support during the research.

\section{REFERENCES}

1. Haynes RK, Vonwiller SC. Extraction of artemisinin and artemisinic acid: Preparation of artemether and new analogues. Trans R Soc Trop Med Hyg 1994;88 Suppl 1:S23-6.

2. Sweetman SC. Martindale: The Complete Drug Reference. $36^{\text {th }}$ ed. London: Pharmaceutical Press; 2009. p. 598-9.

3. Sweetman SC. Martindale: The Complete Drug Reference. $36^{\text {th }}$ ed. London: Pharmaceutical Press; 2009. p. 605.

4. Makanga M, Krudsood S. The clinical efficacy of artemether/ lumefantrine (Coartem). Malar J 2009;8 Suppl 1:S5.

5. Mutabingwa TK, Adam I. Use of artemether-lumefantrine to treat malaria during pregnancy: What do we know and need to know? Expert Rev Anti Infect Ther 2013;11(2):125-35.

6. César Ida C, Andrade Nogueira FH, Antônio Pianetti G. Simultaneous determination of artemether and lumefantrine in fixed dose combination tablets by HPLC with UV detection. J Pharm Biomed Anal 2008;48(3):951-4.

7. Huang L, Lizak PS, Jayewardene AL, Marzan F, Lee MN, Aweeka FT. A modified method for determination of lumefantrine in human plasma by HPLC-UV and combination of protein precipitation and solid-phase extraction: Application to a pharmacokinetic study. Anal Chem Insights 2010;5:15-23

8. Kalyankar TM, Kakde RB. Reversed-phase liquid chromatographic method for simultaneous determination of artemether and lumefantrine in pharmaceutical preparation. Int $\mathrm{J}$ ChemTech Res 2011;3(3):1722-7.

9. Suleman S, Vandercruyssen K, Wynendaele E, D'Hondt M, Bracke N, Duchateau L, et al. A rapid stability-indicating, fused-core HPLC method for simultaneous determination of $\beta$-artemether and lumefantrine in anti- 
malarial fixed dose combination products. Malar J 2013;12:145.

10. Gupta NK, Babu AM, Gupta P. Simultaneous estimation of artemether and lumefantrine by RP-HPLC method development in pharmaceutical tablet dosage form. Int J Pharm Erudition 2013;3(1):10-7.

11. Gaikwad S, Tajne M, Gaikwad N, Daud A, Lonare D, Lonare M. HPLC method development and validation for simultaneous estimation of antimalarial drugs artemether and lumefantrine. Int J Pharm Sci Health Care 2016;6:24-31.

12. ICH Harmonized Tripartite Guideline International Conference on Harmonization of Technical Requirements for Registration of Pharmaceuticals for Human Use. Validation of Analytical Procedures: Text and Methodolgy; 2005. 